\title{
Teachers' views on effective classroom management: a mixed-methods investigation in Western Australian high schools
}

\author{
Helen Egeberg ${ }^{1}$ (D) $\cdot$ Andrew McConney ${ }^{2} \cdot$ Anne Price $^{2}$
}

Received: 29 October 2019 / Accepted: 11 June 2020 / Published online: 30 June 2020

(c) The Author(s) 2020

\begin{abstract}
Teachers' views about teaching, learning and school experiences are important considerations in education. As the central participants in classroom interactions, students and teachers naturally have strong views about what it takes to manage learning and surrounding behaviours effectively. With this in mind and because we believe that ignoring the thinking of either of these stakeholders would be to the detriment of teaching and teacher education, we focused on hearing and understanding teachers' voices about teaching, learning and classroom management. Our aim was to further clarify teachers' perspectives on how educators create quality learning environments as well as gathering their views of various disciplinary interventions, their perceptions of challenging students and their sense of efficacy for classroom management in order to inform both policy and practice in teacher education. A survey was conducted with 50 secondary school teachers to capture their views on their classroom experiences. Follow up interviews with teachers identified by students as effective in their classroom management provided consistent reports that effective classroom managers build positive relationships with their students, manage their classrooms by establishing clear boundaries and high expectations, and engage students in their learning.
\end{abstract}

Keywords Classroom management · Teacher-student relationship $\cdot$ Teacher perceptions

\section{Introduction}

Classroom management is universally seen as a key dimension of teachers' work as reflected in research that places it among the most required teaching skills (Huntly 2008; Jones 2006; McKenzie et al. 2011). Teachers' skill in classroom management is often cited as the dimension of teachers' work that is the most challenging and the area of training that many beginning and pre-service teachers feel is lacking (Australian Education Union 2009; Evertson and Weinstein 2006; Kafman and Moss 2010; Peters 2012; Putman 2009; Ritter

Helen Egeberg

h.egeberg@ecu.edu.au

1 Edith Cowan University, 2 Bradford Drive, Mt Lawley, WA 6050, Australia

2 Murdoch University, 90 South Street, Murdoch, WA 6150, Australia 
and Hancock 2007; Romano 2008). In order to enhance or transform these skills, as well as inform policy and practice with regard to classroom management it is important to investigate and understand teachers' views and beliefs, as their "philosophy about the nature of teaching, learning and students determines the type of instruction and discipline we have in schools and classrooms" (Freiberg 1999, p. 14).

As the central participants in classroom interactions, students and teachers naturally have strong views about what it takes to manage learning and surrounding behaviours effectively (Lewis 2001; Lewis et al. 2008; Roache and Lewis 2011; Sullivan et al. 2014; Woolfolk Hoy and Weinstein 2006) With this in mind and because we believe that ignoring the thinking of either of these stakeholders would be to the detriment of teaching and teacher education, we focused on hearing and understanding teachers' voices about teaching, learning and classroom management. Our aim is to further clarify teachers' perspectives on how educators create quality learning environments as well as gathering their views of various disciplinary interventions, their perceptions of challenging students and their sense of efficacy for classroom management, in order to inform both policy and practice in teacher education.

Students' perceptions of teachers who create and maintain safe and supportive learning environments, and their classroom experiences, have been previously examined (Egeberg and McConney 2017). Despite varying school contexts, students identified effective classroom managers as teachers who meet students' needs by developing caring relationships and controlling the classroom environment while fostering student responsibility and engaging students in their learning (Egeberg and McConney 2017). Few researchers, however, have investigated the views of both students and teachers in the same study, ensuring that setting and context are similar (Woolfolk Hoy and Weinstein 2006; Roache and Lewis 2011). In the current research, teachers at the same schools as the student participants in our 2017 study were surveyed about their views on classroom management, including those identified by their students as being effective managers. Teachers in this smaller group were also subsequently interviewed. Previous studies have reported teachers' perceptions about education and teaching practices; the significance of this research, however, is that it examines the views and beliefs of teachers who previously had been identified by their students as effective in creating and maintaining quality learning environments.

\section{Literature review}

The term classroom management is a conceptual umbrella, one that is often used interchangeably with discipline, but is also seen as distinct from classroom instruction (Egeberg et al. 2016). Research in the 1980s, however, argued that teachers' management and instruction are not separate, but are inextricably interwoven and complex. "Classroom management is certainly concerned with behaviour, but it can also be defined more broadly as involving the planning, organization and control of learners, the learning process and the classroom environment to create and maintain an effective learning experience" (Doyle 1986, p. 396). It is this definition, as well as the view provided in the Australian Professional Standards for Teachers that we subscribe to here (AITSL 2011). Using Woolfolk Hoy and Weinstein's (2006) three interwoven aspects of teacher practice: classroom management (actions to create a productive, orderly learning environment); discipline (actions to elicit change in students' behaviour); and, socialization (actions to help students fulfil their responsibilities) we aimed to examine high school teachers' views and beliefs to 
better understand what teachers do to create and maintain safe and supportive learning environments.

Historically, teacher education has relied on scales focused on a narrower concept of discipline (Glickman and Tamashiro 1980; Wolfgang and Glickman 1986), rather than the broader concept of classroom management that encompasses both behaviour management (BM) and instructional management (IM). "Examination of the literature on teacher knowledge, beliefs, and perceptions indicates that we have potentially valuable scales and inventories that have rarely been used in research" (Woolfolk Hoy and Weinstein 2006, p. 211). One of the scales that these authors refer to is Martin, Yin and Baldwin's Attitudes and Beliefs on Classroom Control, which was later revised as the Behavior and Instructional Management Scale (BIMS) (Martin et al. 1998; Martin and Sass 2010). The BIMS is important in the study of differences that may exist between teachers' beliefs and their capacity to implement them within the classroom (Martin et al. 1998, 2007; Martin and Sass 2010). This, we believe, provides an appropriate starting point from which to examine teachers' beliefs and perspectives of the more encompassing construct of "classroom management". Although the BIMS is based on the Beliefs on Discipline Inventory developed by Wolfgang and Glickman (1986), it nevertheless reflects a broader concept encompassing teachers' perceptions of their classroom management, in terms of both BM and IM around which Martin and her colleagues developed and validated the BIMS (Martin and Sass 2010). Teachers' efforts aimed at preventing misbehaviour, along with how a teacher responds to misconduct, are related to BM, whereas IM includes the plans, goals, and tactics teachers use to deliver instruction in a classroom.

Research shows that teachers' interactions with students are often linked to their beliefs about young people and how they develop (Erden and Wolfang 2004). Glickman and Tamashiro (1980) and Wolfgang (1995) conceptualized a framework to explain teacher beliefs and approaches along a control continuum, with relationship-listening beliefs and non-interventionist approaches at the least controlling end, rules/rewards-punishment beliefs and interventionist approaches at the most controlling end, and confronting-contracting beliefs and interactionalist approaches in the middle. A more recent conceptual framework clusters discipline theories across a similar continuum from autocratic through authoritative and mixed to egalitarian. This continuum also varies according to distribution of power in classrooms, from teacher-centred, to shared, to student-centred, and from a focus on student behaviour only, to a compound focus on behaviour, cognition, emotion and relationships (Porter 2007).

In the past, various studies had shown that many teachers and even some policies, reflected very traditional views about discipline (Adey et al. 1991; Oswald et al. 1991, 1994). These studies identified four orientations to classroom discipline: traditional, liberal progressive, socially critical, and laissez-faire. Teachers who hold a traditional orientation have many beliefs in common with an interventionist rules-rewards philosophy as depicted in Wolfgang's (1995) framework. Teachers with a liberal progressive orientation believe in a democratic approach in which students share power, are part of decision-making, and cooperation and social skills are essential for participation. Teachers who hold a socially critical stance see student misbehaviour as resistance against an unfair system with repressive and at times inappropriate practices. The laissez faire stance is essentially congruent with the non-interventionist, described in Wolfgang's framework. Although few teachers adhered completely to one type of view, nearly $70 \%$ of secondary teachers identified as traditionalist, with the remainder mainly liberal progressive.

In a 2001 study, over 3500 students from years 6, 7, 9 and 11 in Australian schools were asked to complete a questionnaire that documented the extent to which their 
teachers used various discipline strategies. The students' responses were used to conceptualise teachers' classroom discipline behaviour in terms of three styles: influence which includes the use of listening and clarifying techniques to negotiate solutions; group management which includes class meetings, agreed management of behaviour and non-punitive teacher responses to enable students to make better choices; and, control which involves rules, rewards and a clear hierarchy of increasingly severe punishments for misbehaviour (Lewis 2001). Secondary students reported that even though some teachers used techniques such as hints and discussion, (aligned with an influence, relationship-based approach), many teachers tended toward the use of punishment. This suggested that most teachers held a controlling or coercive style of management. The study also showed that "students who receive more relationship-based discipline are less disrupted when teachers deal with misbehaviour and generally act more responsibly in that teacher's class. In contrast, the impact of coercive discipline appears to be more student distraction from work and less responsibility" (Lewis 2001, p. 315).

In a 2014 study, Sullivan, Johnson, Owens and Conway, asked 1380 Year 12 teachers in South Australia to identify the range and frequency of student behaviours requiring disciplinary response and to explain how they responded. Analysis of responses to the web-based survey showed that low-level disruptive behaviours occurred most frequently with very little aggressive or antisocial behaviour. The study showed that disengaged behaviours were the most prevalent suggesting that these "have more to do with factors within a teacher's control than with those located within the student" (Sullivan et al. 2014, p. 53). Instead of using responses that may address the underlying cause of the misbehavior, such as ways to engage students positively in their learning, the study found that teachers tended to implement a "stepped approach" involving increasingly severe coercive techniques. As Maguire et al. (2010) argued, moving the focus from controlling discipline approaches to ways of engaging students offers opportunities for teachers to preclude or divert unproductive student behaviour and reduce their reliance on punitive intervention strategies.

Thus, it is clear that determining what (typically) is and what is not effective classroom management is a complex issue (De Jong 2005). Many researchers have attempted to conceptualise guiding principles and practices that could be used to support the development of appropriate approaches to managing student behaviour (McLeod et al. 2003). In essence, "teachers who approach classroom management as a process of establishing and maintaining effective learning environments tend to be more successful than teachers who place more emphasis on their roles as authority figures or disciplinarians" (Brophy 1988, p. 1). It is the ability of a teacher to know not only what they want to teach, but also how they will organise and structure it for their students and their circumstances that makes all the difference, creating a healthy, caring classroom culture where all students, and teachers, can thrive (Bennett and Smilanich 2012).

The current study investigates this broader view of classroom management. It encompasses both behaviour management (BM) which includes pre-planned efforts to prevent misbehavior as well as teachers' response to it, specifically establishing expectations, monitoring and teaching behaviour and providing opportunities for student input and, instructional management (IM), which addresses teachers' pedagogical aims and methodologies and includes aspects such as planning and structuring routines as well as the use of various instructional techniques to enable active participation and engagement. Consequently, this research gives voice to the views and experiences of not just teachers, but teachers who have been nominated by their students as being effective in creating and maintaining quality learning environments, centered on effective classroom management. The overarching 
question that frames the study is, "What are effective teachers' views of classroom management?" Component research questions include:

1. What are secondary teachers' orientations toward classroom management?

2. To what extent do teachers' classroom management views differ according to school sector, school socioeconomic status (SES) or gender? and

3. How do teachers, who have been identified by their students as being effective, manage their classrooms?

\section{Methods}

\subsection{Research design}

The purpose of this study is to examine the perceptions of secondary school teachers about their classroom management, at a variety of high schools in Western Australia. For educational researchers holding a pragmatic worldview, the choice of research design is guided by the research question(s) asked, rather than epistemology, with a view to further understanding the phenomenon being studied and to add value, in a practical sense. In this study, our key aim is to advance our collective understanding of effective classroom management and to broaden the perspective with which it is viewed, thereby facilitating translation into practice. In achieving this, both description and explanation are important. Descriptions involve drawing a picture of what is happening, and "attempting to make complicated things understandable" (Punch 2000, p. 15). Explanation involves examining the 'how', as well as describing the 'what' because this has the potential to influence our future practice. An increasingly used research approach to achieving both description and explanation is to employ both quantitative and qualitative perspectives on the phenomenon of interestin this case teachers' classroom management. For this reason, a mixed methods research design was chosen-with one type of data collection (e.g., qualitative) offsetting potential limitations or lack of depth in the other, and vice versa. Specifically, this study used a sequential explanatory design, with two distinct phases, quantitative followed by qualitative (Creswell 2014). As Greene et al. (1989) have explained, a mixed methods approach provides depth and detail to a study and potentially uncovers new insights into participant experiences. While a quantitative method allows stronger generalisability and comparability, and better accommodates investigating the 'what', a qualitative approach allows deeper examination to build a more complete picture of effective classroom management, and better accommodates answering 'how' or 'why' questions. In addition to its mixed methods design, the study was also interpretive in that high school teachers described their views through surveys (quantitative) and interviews (qualitative); we summarized, analyzed and interpreted these views to advance our understanding of effective classroom management.

Previously, in an earlier phase of this research, 360 students from a variety of public and private secondary schools had participated in a study that catalogued and examined students' views of effective classroom management. Students were recruited from metropolitan high schools in Perth, Western Australia (WA), and comprised Year 9 and 10 students (255 males and 105 females) ranging in age between 14 and 16 years. The overarching intention of that study was to better understand, from the perspective of their students, what teachers do to create and sustain safe and supportive learning environments. In this earlier phase, we used the Students Perceptions Survey (SPS) from Cambridge Education and 
Tripod Survey Assessments that allowed students to characterise what it is that teachers do in effectively managing their classrooms, and to nominate some teachers they believed did this well (Egeberg and McConney 2017).

\subsection{Participants}

In the current study, we invited teacher-participants via email asking them to take part in a survey and follow up interview. Participants comprised 50 secondary school teachers, (23 males and 27 females), working in six schools representing the three school sectors in Western Australia (WA) - the Association of Independent Schools of WA (AISWA), the WA Department of Education (DOE) and Catholic Education (CEWA). Of the 50 teachers who completed the first phase (survey), their students had nominated 25 (10 male and 15 female) as effective classroom managers. Twenty-two of these teachers ( 9 male and 13 female) were subsequently available for individual interviews. Across the six schools involved, between 3 and 5 teachers were interviewed from each school, ranging in age from 26 to 62 years. Table 1 provides a breakdown of this study's teacher participants by school characteristics and gender. For the purpose of this study we combined AISWA and CEWA schools into one group and classified these as "Private". School socioeconomic status (SES) was determined via the Index of Community Socio-Educational Advantage (ICSEA) which uses two data sources: student enrolment records including information relating to parent occupation, school education, non-school education and language background (direct data) and Australian Bureau of Statistics (ABS) census data (indirect data). ICSEA values range from around 500 (extremely socio-educationally disadvantaged) to about 1300 (very advantaged) (ACARA 2012). Any particular school's ICSEA is the averaged value representing all students in the school. For this study, schools with an average ICSEA above 1100 were considered higher SES, and those with ICSEA values less than 1100 were considered lower SES.

\subsection{Instruments}

Two instruments were used for data collection: the first was a survey that allowed teachers to describe how frequently they use particular classroom management strategies or techniques. The Behaviour and Instructional Management Survey (BIMS) is a relatively brief, psychometrically validated instrument that measures how frequently teachers report using particular techniques, both behavioural and instructional. Martin and Sass (2010) used exploratory factor analysis (EFA) in validating the BIMS. Analysis of the Behavior

Table 1 Number of teacherparticipants by school sector, gender and SES

\begin{tabular}{|c|c|c|c|c|}
\hline & \multicolumn{2}{|c|}{ Private } & \multicolumn{2}{|c|}{ Public } \\
\hline & Male & Female & Male & Female \\
\hline $\begin{array}{l}\text { Higher SES schools } \\
(n=3 \text {; ICSEA values } \\
\text { above } 1100)\end{array}$ & 10 & 11 & 2 & 4 \\
\hline $\begin{array}{l}\text { Lower SES schools } \\
\qquad(n=3 ; \text { ICSEA values } \\
\text { up to } 1100)\end{array}$ & 2 & 3 & 10 & 8 \\
\hline Total & 12 & 14 & 12 & 12 \\
\hline
\end{tabular}


Management subscale showed good internal consistency (Cronbach's $\alpha=0.8$ ), with an average inter-item correlation of 0.377 (SD .091). The average corrected item-total correlation for this subscale was 0.5 (SD .071), suggesting good item discrimination. Results for the Instructional Management subscale also showed good internal consistency $(\alpha=0.8)$, with an average inter-item correlation of 0.365 (SD .092). The average corrected item-total correlation for this subscale was also 0.5 (SD .086), again suggesting good item discrimination (Martin and Sass 2010). Overall, Martin and Sass's (2010) EFA results provided solid evidence of discriminant and convergent validity, good internal consistency and strong item discrimination. Using the BIMS as an inventory, we sought to determine the frequency with which 50 teachers-participants reported engaging in various classroom management behaviours. We emphasize that using the BIMS as a definitive assessment of teachers' approach to classroom management was not the main purpose; rather, our intention was to "warm up" teacher-participants in articulating or focusing their views about classroom management during individual interviews.

Item 25, the last item on the teacher survey, was an open-ended question that asked teachers what they do that helps to create and maintain safe and supportive learning environments. This aspect of our data collection and analysis, and that of the ensuing teacherparticipant interviews, centered on a qualitative approach, enabling further exploration of these teachers' perspectives. We employed an inductive process of gathering detailed information from participants, in this case teachers, and then formed this into themes (Creswell 2014). The data were first coded thematically using NVivo, a qualitative analysis software that provides word frequencies and key words in the context of concepts like classroom management, caring relationships, behaviour and instruction. Using text search and word frequency queries we added annotations to record our insights and this in turn assisted with identifying patterns across the responses to identify connections and themes that informed our development of answers to the research questions posed.

The second phase of data collection comprised individual interviews with 22 selected teacher participants. These participants were chosen from those who had volunteered via the survey and who also had been selected by their students as effective in creating and maintaining safe and supportive learning environments. The interview topics were developed from research into effective classroom management (Ferguson 2010; Garza et al. 2010; Lewis 2001; Lewis et al. 2008; Woolfolk Hoy and Weinstein 2006). The topics were also used as the basis for further clarifying teachers' perspectives about effective classroom management as well as their perceptions of the frequency, efficacy and acceptability of various disciplinary interventions. The interviews were semi-structured, audio taped with consent for future transcription, and about $30 \mathrm{~min}$ in duration.

\section{Results}

\subsection{Phase 1: survey}

This study posed the following questions:

1. What are secondary teachers' orientations toward classroom management?

2. To what extent do teachers' classroom management views differ according to school sector, school socioeconomic status (SES) or gender? and 
3. How do teachers, who have been identified by their students as being effective, manage their classrooms?

The BIMS provides a framework that allows characterisation and summarization of the strategies or techniques teachers use in managing their classrooms. On the BIMS, teachers report the frequency with which they use each of 24 briefly described strategies, as shown in Table 2 for the 50 teacher-participants in this study.

In answering research question 1, of the classroom management techniques used by teachers, the four that showed the highest frequency of use, across all teachers, were: $I$ use whole class instruction to ensure a structured classroom (IM \#2); I redirect students back to the topic when they get off task (BM \#15); I direct the students' transition from one learning activity to another (IM \#16); and, I use a teaching approach that encourages interaction among students (IM \#24). As shown in Table 2, for these four items, all teachers (100\%) reported using the strategy sometimes, often or always. Only one of the 24 strategies suggested a low proportion of teachers using the technique frequently. Specifically, $44 \%$ of teachers indicated that when a student talks to a neighbour, they would move the student away from other students (BM \#7), sometimes (36\%) or often (8\%). This type of control or compliance strategy would seem not to be a major aspect of these teachers' approaches to classroom management. In another example, only a small majority (56\%) indicated that if a student's behaviour is defiant, I demand that they comply with my rules (BM \#23) sometimes (20\%), often (26\%) or always (10\%).

Using the scoring system that Martin and Sass designed for the BIMS, with Always allocated a " 5 " to Never receiving a "1", and scoring for some items being reversed, we examined responses for items aligned with three key approaches to classroom management: a controlling, interventionist approach; an interactionalist, needs-based approach, and; a less controlling non-interventionist approach. It is important to note that there are no specific cut scores for identifying teachers as interventionist, interactionalist, or noninterventionist, and this was certainly not our intention. It was also the case, however, that we viewed higher scores on the combined scales of the BIMS as indicative of a tendency toward a more controlling approach, lower scores suggestive of a less controlling approach and those centrally located indicative of an interactionalist approach, as had been the case in Martin and Sass' classroom management research (2010). In this, we found that all of the 25 teachers identified by students as creating and maintaining effective learning environments most frequently used an interactionalist approach, whereas a more modest $74 \%$ of teachers not nominated by students indicated that they most frequently use this approach.

In answering research question 2 (To what extent do teachers' classroom management views differ according to school sector, school socioeconomic status (SES) or gender?) we compared BIMS response distributions from teachers across school sectors (public and private), school SES (higher and lower ICSEA) and teacher gender. Very little difference was evident between groups of teachers in terms of what techniques they would use frequently in their classrooms. Female teachers comprised 52\% of the teachers surveyed and $60 \%$ of the teacher cohort identified as effective by students. The largest group-based difference noted was for item BM\#3: I limit student chatter in the classroom with $96 \%$ of female teachers suggesting they would use this strategy frequently in comparison to $75 \%$ of male teachers. Two other items showed a notably higher proportion of female teachers indicating frequent use as compared to males: $96 \%$ of female teachers indicated they establish a teaching daily routine in their classroom and stick to it (IM \#8) compared to 79\% of male teachers; and, $81 \%$ of female teachers indicated that they use input from students to create 


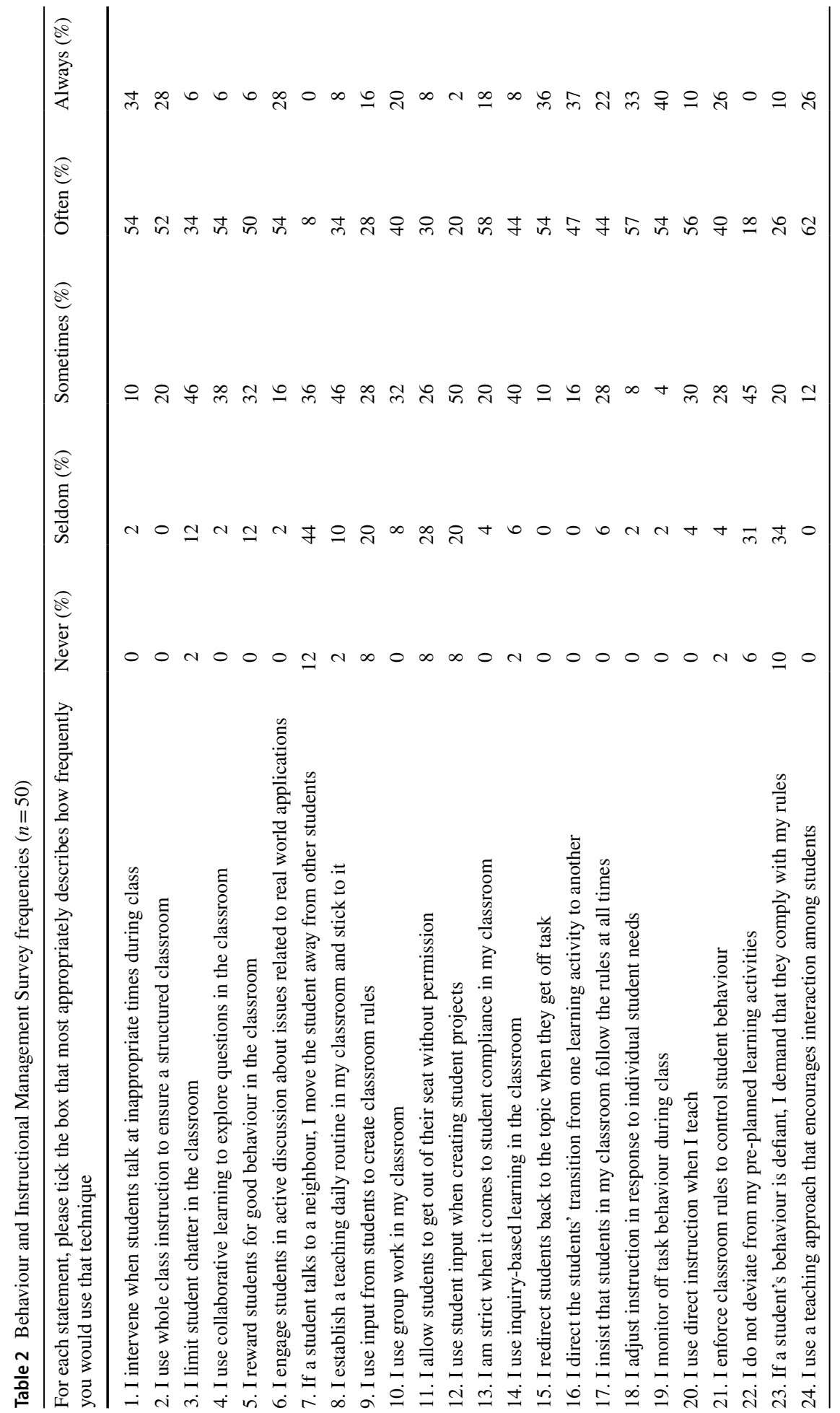


classroom rules (BM \#9) compared to $63 \%$ of males. In contrast $71 \%$ of male teachers said they allow students to get out of their seat without permission (BM \#11) in comparison to $58 \%$ of female teachers.

Similarly, to examine potential differences between teachers nominated by their students as effective classroom managers, and those not, and to answer research question 3 "How do teachers, who have been identified by their students as being effective, manage their classrooms?" we also conducted two statistical tests, the results of which are given in Table 3. We conservatively used non-parametric statistical tests as the data provided via the BIMS are ordinal data. We used Pearson's Chi Squared test to determine whether there was a statistically significant difference between expected and observed frequencies between teachers "nominated as effective" and those "not nominated". On the other hand, Mann-Whitney $U$ is a nonparametric test of the null hypothesis that it is equally likely that a randomly selected value from one population will be statistically different than a value from a second population. Mann-Whitney $U$ can be used to investigate whether two samples were selected from populations having the same distribution. As detailed in Table 3, we found

Table 3 Pearson Chi square and Mann-Whitney $U$ tests of differences between teachers nominated as effective classroom managers versus those not nominated, on 24 BIMS items

\begin{tabular}{llllll}
\hline BIMS Item & Pearson $\chi^{2}$ & $d f$ & $\chi^{2}$ Sig (2-sided $)^{\mathrm{a}}$ & Mann-Whitney $U$ & $\begin{array}{l}\text { Mann- } \\
\text { Whitney } U \\
\text { Sig }^{\mathrm{a}}\end{array}$ \\
\hline 1 & & & & & 0.274 \\
2 & 1.766 & 3 & 0.622 & 363 & 0.67 \\
3 & 0.44 & 2 & 0.803 & 292.5 & 0.699 \\
4 & 2.45 & 4 & 0.654 & 331 & 0.075 \\
5 & 3.575 & 3 & 0.311 & 394 & 0.703 \\
6 & 1.29 & 3 & 0.732 & 330.5 & 0.764 \\
7 & 2.119 & 3 & 0.548 & 298.5 & 0.095 \\
8 & 6.465 & 3 & 0.091 & 232.5 & 0.638 \\
9 & 2.902 & 4 & 0.574 & 290 & 0.69 \\
10 & 4.243 & 4 & 0.374 & 332.5 & 0.068 \\
11 & 5.45 & 3 & 0.142 & 401.5 & 0.371 \\
12 & 3.523 & 4 & 0.474 & 357 & 0.925 \\
13 & 3.4 & 4 & 0.493 & 308 & 0.452 \\
14 & 3.71 & 3 & 0.294 & 278 & 0.344 \\
15 & 4.382 & 4 & 0.357 & 357.5 & 0.752 \\
16 & 0.756 & 2 & 0.685 & 298 & 0.957 \\
17 & 1.094 & 2 & 0.579 & 297.5 & 0.741 \\
18 & 6.632 & 3 & 0.085 & 328.5 & 0.365 \\
19 & 4.267 & 3 & 0.234 & 260 & 0.982 \\
20 & 4.126 & 3 & 0.248 & 311.5 & 0.761 \\
21 & 2.438 & 3 & 0.487 & 298.5 & 0.919 \\
22 & 4.059 & 4 & 0.398 & 280.5 & 0.564 \\
23 & 3.729 & 3 & 0.292 & 273 & 0.108 \\
24 & 3.736 & 4 & 0.443 & 360.5 & 0.28 \\
\hline
\end{tabular}

${ }^{\text {a }}$ Significance level is .05 
that in no case were teacher-participants nominated as effective classroom managers by their students statistically different from teachers not nominated, in terms of the frequencies with which they used the management strategies reflected in the 24 items of the BIMS.

In further examining BIMS responses from the 25 teachers nominated by students as effective classroom managers, compared against the responses of 25 teachers not nominated however, it was the areas of control and interaction that showed some differences in approach between the two groups. Differences in the frequency with which the teachers frequently use a strategy between those nominated and those not are graphically depicted in Fig. 1.

As shown in Fig. 1, for example, $28 \%$ of nominated teachers indicated that they would frequently move a child for talking to their neighbor (BM \#7), compared to $60 \%$ of teachers who were not nominated by their students. (Hence, $28 \%$ minus $60 \%$ results in a negative difference of $32 \%$ suggesting that teachers nominated by their students as effective managers, less frequently use punitive strategies. Nominated teachers more frequently took, it would seem, a flexible approach and less frequently demanded compliance (IM \#22 \& BM \#23). Nominated teachers also more frequently used group work (IM \#10), inquirybased learning (IM \#14) and student input when creating projects (IM\#12) and also more frequently limited chatter in the classroom (BM \#3).

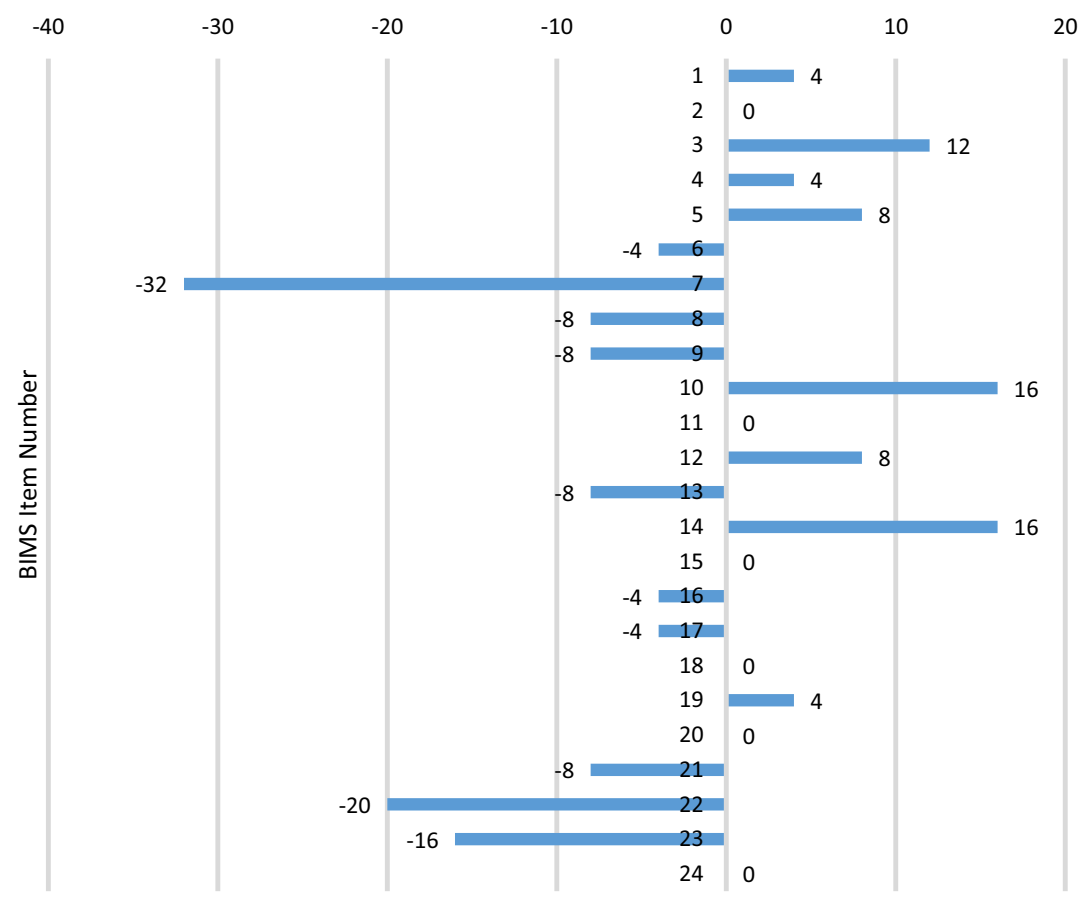

Fig. 1 Differences in percentages of nominated and non-nominated groups of teachers who use BIMS strategies frequently in classroom management. Note: Positive differences (bars to the right) indicate that nominated teachers use a BIMS strategy more frequently; negative differences (bars to the left) mean that nonnominated teachers use the strategy more frequently 
In reviewing the comments made by teachers in response to Question 25 (an open-ended question that asked teachers what they do that helps to create and maintain safe and supportive learning environments), a third construct of classroom management other than the two already determined emerged, that of care. We therefore categorised teachers' responses into one of three emergent themes - instructional management, behaviour management and care-with some comments appearing in more than one category as shown in Table 4.

\subsubsection{Care}

Teachers' building of positive relationships with their students received the greatest proportion of responses, with nearly $43 \%$ of 50 teachers surveyed suggesting this a key strategy. Teachers specified that building positive relationships by showing genuine care and listening to student voices is important in being an effective manager. For example:

Taking the time to get to know your students and build that relationship on a daily basis is, in my opinion, the most important thing a teacher can do.

Coupled with this, the teacher's ability to listen to students and to confer with them on various elements of their learning and school experience was also seen as important:

Positive accountability; the students knowing that they are valued, that they have a voice that is heard.

\subsubsection{Behaviour management}

For many of the teachers nominated as effective by students, care and concern were also manifested in the way they managed the class, and in high expectations. Thirty-nine percent of teachers' responses could be categorized as focused on behaviour management,

Table 4 Percentage of teacher-participants' $(N=50)$ responses to BIMS item \#25 (What do you believe teachers do that helps to create and maintain safe and supportive learning environments?) coded into each theme and sub theme

\begin{tabular}{|c|c|c|c|}
\hline \multirow{2}{*}{$\begin{array}{l}\text { Themes } \\
\text { Sub themes }\end{array}$} & \multicolumn{3}{|l|}{ Percentage of responses } \\
\hline & $\begin{array}{l}\text { Nominated by students as } \\
\text { effective managers }(\%)\end{array}$ & $\begin{array}{l}\text { Not nominated by students as } \\
\text { effective managers (\%) }\end{array}$ & Total (\%) \\
\hline Instructional management & 22.2 & 10 & 32.2 \\
\hline Engage & 12.2 & 6 & 18.2 \\
\hline Explain & 3.8 & & 3.8 \\
\hline Assess & 6.2 & 4 & 10.2 \\
\hline Behaviour management & 17.3 & 21.7 & 39 \\
\hline Expectations & 10.6 & 1.3 & 11.9 \\
\hline Dictate & 0.8 & 20.4 & 21.2 \\
\hline Boundaries & 5.9 & & 5.9 \\
\hline Care & 38.6 & 14.2 & 42.8 \\
\hline Relationships & 21.4 & 0.6 & 22 \\
\hline Confer & 17.2 & 13.6 & 20.8 \\
\hline
\end{tabular}


their ability to establish clear boundaries and high expectations without being rigid, threatening or punitive. For example:

Have high expectations of students in all aspects of their classroom conduct and effort. Treat all students with respect when dealing with them individually or in a group/class situation.

For those teachers not nominated by students a consistent comment was the need for consistency, consequences for all actions and follow-through, seeming to suggest a somewhat more authoritarian view of how student behaviours should be managed.

\subsubsection{Instructional management}

Thirty two percent of the responses could be categorized as related to the theme of instructional management; that is, teachers' ability to engage their students by creating interest, clarifying students' understandings of various concepts and consolidating this understanding especially through the use of formative assessment with useful and appropriate feedback. Those teachers nominated by students considered engaging teaching and clear explanation as paramount in their management of the class:

Show a willingness to be flexible in interpreting and delivering the curriculum in a way that students will find engaging. Make the learning intentions clear. Encourage questions and make mistakes part of learning.

In contrast, those not nominated by students seemed more focused on detailed subject knowledge as opposed to how that subject knowledge was delivered. Teachers also used words like clear, effective, humour, relationship, understanding, interesting, and respect to describe what they do to create and maintain safe and supportive learning environments.

\subsection{Phase 2: interviews}

In further answering research question 3, and indeed the overarching question of this study, the teachers who participated in the interviews were 22 of the 25 nominated by their students as being effective classroom managers. The interviewer posed a series of questions aimed at creating a mental set for participants around student behaviour and effective classroom management. All of the teachers agreed that students choose to behave well in some classes and not so well in others with one surmising what most had suggested: 'how much of that is a conscious choice or a learned response to the context could be different'. A variety of reasons for students' misbehaviour in school were suggested. Many were seen as 'factors outside the teacher's control. It can be the temperature, it can be what they're doing at night, it can be the relationship with their family and it can be problems with their friends.' Two key factors were dominant in the responses given by these teachers:

I think relationship is the main thing. I think kids find it really hard to misbehave when they have a really good relationship with the teacher but I also think that lack of engagement plays a key factor. Some kids will misbehave if they're bored or something's too difficult for them and they're frustrated and they can't do it.

Discipline was not so much about punishing students for infractions as it was teaching them how to behave appropriately and therefore disciplinary interventions needed to be both preventative and corrective. 
Discipline is really all about getting the kids to control themselves and to make better choices. Discipline, I suppose, is about teaching discipline.

In discussion of key techniques used or required to manage classrooms a number of concepts were mentioned, all of which fell into the three key themes developed through analysis of the survey data, and well-articulated by one teacher who said, "look after me, manage my room, and do stuff that's interesting. I think if we've got those three happening, we're in a pretty good situation." The use of various reminders and redirects such as eye contact, minimal use of verbal responses, use of students' names and proximity were considered the "best way to go. Give them chances, keep it low key, scan the class, proximity, body language, all of that is crucial."

The teachers interviewed had mixed opinions on involving students in classroom discipline decisions including creating rules with the students or talking with students to discuss the impact of their behaviours. One teacher explained, "we're not a democracy, we're a benevolent dictatorship." But, others were quick to advocate otherwise:

At the beginning of the year that's what we should all do. I do it by asking kids what they expect in the classroom, if we're going to be productive, what do they expect from me as a teacher, what do they expect from other kids in the room, what do they expect from themselves. Then, based on that, if you had to put some guidelines in place what would they be for this to be a place of work?

When it came to the use of punishment all of the teachers interviewed agreed:

It's such a negative thing to do. There's no relationship-building aspect to it either. You've sort of lost what you've built. Obviously, there has to be consequences if you did something wrong. But punishing and being aggressive, handing out detentions and "scab" duty, it's ineffective because you separate the consequence, not only from the behavior but separate it from yourself. It doesn't do anything, it makes them angry and it doesn't change their behavior. It doesn't teach them, it doesn't encourage them to a better way of behaving.

Encouraging students to a better way of behaving was important amongst all participants.

I don't bribe them with anything. Sometimes it's just a comment or bit of encouragement, or even a call home to say doing well. I often will say things like "It's been a really great lesson today, we've had some really great input, everyone's been focused, I thought the group work was fantastic" that kind of lay it on a bit thick and so it's been really good, and try to mention a few names of, that comment that Susie said, you know that really generated some interesting discussion... rewarding them for their learning.

All teachers interviewed agreed that, "90\% of it [effective classroom management] is building a rapport. Once I've built a rapport then I can train them, both academically and socially. I think if you are engaging and interactive and actually show that you care about them and about their progress. That goes a long way into establishing a successful classroom." 


\section{Discussion}

Effective classroom management is a key dimension of teacher preparation and practice, and an important factor in early-career teacher retention or attrition (Buchanan et al. 2013). In an effort to improve teachers' classroom management and its development within Initial Teacher Education (ITE) programs, it seems important to take strong consideration of teachers' views of the practices that comprise positive learning environments. Recognizing the equal importance and value of students' views about what happens in the classrooms (OECD 2014), this study investigates the beliefs and self-reported actions of teachers that students nominated as effective in creating and maintaining quality learning environments.

The aim of this study was to examine the views of teachers that students suggest manage their classes well to ascertain what their approaches are and how they manage the behaviours of the students in their classrooms. Our analysis of teachers' survey responses showed that the two constructs of effective classroom management, instructional and behavioural management, were certainly evident in all teachers' classrooms with most indicating their preference for techniques that are more consistent with an interactionalist approach. However, $16 \%$ of teacher-participants also suggested a preference for a more corrective and controlling approach in their classroom management. In comparing the views of those nominated by students with those not, teachers' use of compliance and coercion strategies showed the largest differences between the two groups, despite not being statistically different. However, all teachers nominated by students as effective reflected a largely interactionalist rather than interventionist approach to classroom management. This would seem to be consistent with research that suggests that most success comes from those teachers who exhibit interactionalist traits (Brophy 1988; Lewis 2001; Maguire et al. 2010).

In analysing the open-ended question that asked teachers what they do that helps to create and maintain safe and supportive learning environments, the differences between those nominated by students and those not became wider and clearer. Responses from those teachers not nominated by students show a much greater reliance on imposing and maintaining control, with $20 \%$ of their comments referring to the need to regulate and enforce rules through the use of consequences such as detentions or time out. Interestingly, over $20 \%$ of those nominated by students referred instead to building caring relationships as a key element in effective classroom management. This led us to suggest a third key construct of classroom management needing attention, that of care for students.

Interviews with teachers nominated by students further consolidated the three constructs of effective classroom management: caring relationships, behaviour management and instructional management. Participant-teachers believe building rapport through caring for their students' well-being, as the key to building positive relationships. They indicated that trust and encouragement were fundamental aspects of their relationships with students in addition to high expectations and appropriate challenges. These teachers held students accountable but also fostered student responsibility with support and structure. They firmly believed in creating learning experiences for their students that were varied and engaging.

A limitation of this study was not being able to verify the views of these teachers in observed practice. An obvious extension of this research would be to observe some of these teachers in the classroom, to further develop and highlight key practices that effectively manage students and their learning environment. Core findings from this study, however, re-affirm that effective classroom management is multidimensional including caring relationships, high expectations and opportunities for engagement, participation and contribution. This has important implications for how we prepare new teachers, for supporting 
early career teachers and for teachers' ongoing professional learning. Do we attend sufficiently to the multidimensionality of classroom management in our initial teacher education programs? Are we providing impactful, research based professional learning for teachers, that offers support and mentoring as well as skills-based training?

Furthermore, at the macro policy level, these findings should be used to inform standards-setting authorities such as the Australian Institute for Teaching and Leadership (AITSL) as part of ongoing reviews of policy instruments, including the Australian Professional Standards for Teachers (AITSL 2011) and Initial Teacher Education mandated program accreditation standards (AITSL 2018). Any such reviews would greatly benefit from considering the views of teachers identified by students as effective classroom managers. As many of the teachers in this study suggested that students themselves had been a great influence on their knowledge and understanding of how to effectively manage their classrooms, perhaps greater value could be placed on the views of those we seek to most influence-the students themselves. It seems important to also note that while building positive relationships and having high expectations may be more difficult to regulate, measure and quantify than some other pedagogical practices, they were nevertheless considered by both students and teachers in this study to be of central and critical importance.

Open Access This article is licensed under a Creative Commons Attribution 4.0 International License, which permits use, sharing, adaptation, distribution and reproduction in any medium or format, as long as you give appropriate credit to the original author(s) and the source, provide a link to the Creative Commons licence, and indicate if changes were made. The images or other third party material in this article are included in the article's Creative Commons licence, unless indicated otherwise in a credit line to the material. If material is not included in the article's Creative Commons licence and your intended use is not permitted by statutory regulation or exceeds the permitted use, you will need to obtain permission directly from the copyright holder. To view a copy of this licence, visit http://creativecommons.org/licenses/by/4.0/.

\section{References}

Adey, K., Oswald, M., \& Johnson, B. (1991). Discipline in South Australian schools: A survey of teachersSurvey no 1: Teachers in metropolitan schools (Education Department of South Australia). Adelaide: University of South Australia.

Australian Curriculum, Assessment and Reporting Authority (ACARA). (2012). Guide to understanding ICSEA (Index of Community Socio-educational Advantage) values. Retrieved October 5, 2017 from http://www.acara.edu.au/_resources/Guide_to_understanding_icsea_values.pdf.

Australian Education Union (AEU). (2009). New educators survey 2008. Retrieved November 15, 2014 from http://www.aeufederal.org.au/Publications/2009/Nesurvey08res.pdf.

Australian Institute for Teaching and School Leadership. (2011). National professional standards for teachers. Retrieved March 22, 2016 from http://www.aitsl.edu.au/docs/default-source/apst-resources/austr alian_professional_standard_for_teachers_final.pdf.

Australian Institute for Teaching and School Leadership. (2018). Accreditation of initial teacher education programs in Australia-Standards and procedures. Retrieved December 17, 2018 from https://www. aitsl.edu.au/docs/default-source/national-policy-framework/accreditation-of-initial-teacher-educationprograms-in-australia.pdf.

Bennett, B., \& Smilanich, P. (2012). Power plays: Moving from coping to cooperation in your classroom. Saskatoon: Pearson Education.

Brophy, J. (1988). Educating teachers about managing classrooms and students. Teaching and Teacher Education, 4, 1-18.

Buchanan, J., Prescott, A., Schuck, S., Aubusson, P., Burke, P., \& Louviere, J. (2013). Teacher retention and attrition: Views of early career teachers. Australian Journal of Teacher Education, 38(3), 8.

Creswell, J. (2014). Research design: Qualitative, quantitative, and mixed methods approaches (4th ed.). Thousand Oaks: Sage Publications. 
De Jong, T. (2005). A framework of principles and best practice for managing student behaviour in the Australian education context. School Psychology International, 26, 353-370.

Department of Education and Science (DES). (1989). Discipline in schools (England and Wales). London: DES.

Doyle, W. (1986). Classroom organization and management. In M. Wittrock (Ed.), Handbook of research on teaching (3rd ed., pp. 392-431). New York: McMillian.

Egeberg, H., \& McConney, A. (2017). What do students believe about effective classroom management? A mixed-methods investigation in Western Australian high schools. The Australian Educational Researcher. https://doi.org/10.1007/s13384-017-0250-y.

Egeberg, H. M., McConney, A., \& Price, A. (2016). Classroom management and national professional standards for teachers: A review of the literature on theory and practice. Australian Journal of Teacher Education, 41(7), 1-18.

Erden, F., \& Wolfang, C. H. (2004). An exploration of the differences in prekindergarten, kindergarten, and first grade teachers' beliefs related to discipline when dealing with male and female students. Early Child Development and Care, 174(1), 3-11.

Evertson, C. M., \& Weinstein, C. S. (2006). Handbook of classroom management: Research, practice, and contemporary issues. Mahwah, NJ: Erlbaum.

Ferguson, R. F. (2010). Student perceptions of teaching effectiveness: Discussion brief. Cambridge, MA: National Center for Teacher Effectiveness and the Achievement Gap.

Freiberg, J. H. (1999). Beyond behaviorism: Changing the classroom management paradigm. Boston: Allyn and Bacon.

Garza, R., Ryser, G., \& Lee, K. (2010). Illuminating adolescent voices: Identifying high school students' perceptions of teacher caring. Empirical Research, 7(4), 1-16.

Glickman, C. D., \& Tamashiro, R. T. (1980). Clarifying teachers' beliefs about discipline. Educational Leadership, 37, 459-464.

Greene, J. C., Caracelli, V. J., \& Graham, W. F. (1989). Toward a conceptual framework for mixedmethod evaluation designs. Educational Evaluation and Policy Analysis, 11(3), 255-274.

Huntly, H. (2008). Teachers' work: Beginning teachers' conceptions of competence. The Australian Educational Researcher, 35(1), 125-145.

Jones, V. (2006). How do teachers learn to be effective classroom managers? In C. M. Evertson \& C. $\mathrm{S}$. Weinstein (Eds.), Handbook of classroom management: Research, practice and contemporary issues (pp. 887-908). Mahwah, NJ: Lawrence Erlbaum.

Kafman, D., \& Moss, D. M. (2010). A new look at pre-service teachers' conceptions of classroom management and organisation: Uncovering complexity and dissonance. The Teacher Educator, 45(2), $118-136$.

Lewis, R. (2001). Classroom discipline and student responsibility: The students' view. Teaching and Teacher Education, 17(3), 307-319.

Lewis, R., Romi, S., Qui, X., \& Katz, Y. (2008). Students' reaction to classroom discipline in Australia, Israel, and China. Teaching and Teacher Education, 24, 715-724.

Maguire, M., Ball, S., \& Braun, A. (2010). Behaviour, classroom management and student control: Enacting policy in the English secondary school. International Studies in Sociology of Education, 20(2), 153-170.

Martin, N. K., \& Sass, D. A. (2010). Construct validation of the behavior and instructional management scale. Teaching and Teacher Education, 26(5), 1124-1135.

Martin, N. K., Yin, Z., \& Baldwin, B. (1998). Construct validation of the attitudes and beliefs on classroom control inventory. Journal of Classroom Interaction, 33(2), 6-15.

Martin, N. K., Yin, Z., \& Mayall, H. (2007). The attitudes \& beliefs on classroom control inventory-revised and revisited: A continuation of construct validation. Journal of Classroom Interaction, 42(2), 11-20.

McKenzie, P., Rowley, G., Weldon, P., \& Murphy, M. (2011). Staff in Australia's schools 2010. Report prepared for the Department of Education, Employment and Workplace Relations. Melbourne: Australian Council for Educational Research (ACER).

McLeod, J., Fisher, J., \& Hoover, G. (2003). The key elements of classroom management: Managing time and space, student behavior, and instructional strategies. Alexandria, VA: Association for Supervision and Curriculum Development.

Organisation for Economic Cooperation and Development (OECD). (2014). Education policy outlook: Making reforms happen. Retrieved from March 22, 2016 https://www.oecd.org/edu/EPO\%20201 5_Highlights.pdf.

Oswald, M., Johnson, B., \& Adey, K. (1991). Discipline in schools: A Survey of teachers in country schools. Research Report No. 2, School Discipline Research Group, Faculty of Education, University of South Australia, Adelaide. 
Oswald, M., Whitington, V., Dunn, R., \& Johnson, B. (1994). Discipline in schools: A survey of teachers in independent schools. Research Report No. 3, School Discipline Research Group, Faculty of Education, University of South Australia, Adelaide.

Peters, J. H. (2012). Are they ready? Final year pre-service teachers' learning about managing student behaviour. Australian Journal of Teacher Education, 37(9), 18-42.

Porter, L. (2007). Student behaviour. Theory and practice for teachers (3rd ed.). Crows Nest: Allen \& Unwin.

Punch, K. (2000). Developing effective research proposals. London: SAGE.

Putman, S. M. (2009). Grappling with classroom management: The orientations of pre-service teachers and impact of student teaching. The Teacher Educator, 44(4), 232-247.

Ritter, J. T., \& Hancock, D. R. (2007). Exploring the relationship between certification sources, experience levels, and classroom management orientations of classroom teachers. Teaching and Teacher Education, 23(7), 1206-1216.

Roache, J., \& Lewis, R. (2011). Teachers' views on the impact of classroom management on student responsibility. Australian Journal of Education, 55(2), 132-146.

Romano, M. (2008). Successes and struggles of the beginning teacher: Widening the sample. The Educational Forum, 72(1), 63-78.

Sullivan, A. M., Johnson, B., Owens, L., \& Conway, R. (2014). Punish them or engage them? Teachers' views of unproductive student behaviours in the classroom. Australian Journal of Teacher Education, 39(6), 43-56.

Wolfgang, C. H. (1995). Solving discipline problems: Strategies for classroom teachers (3rd ed.). Boston: Allyn and Bacon.

Wolfgang, C. H., \& Glickman, C. D. (1986). Solving discipline problems: Strategies for classroom teachers (2nd ed.). Boston: Allyn and Bacon.

Woolfolk Hoy, A., \& Weinstein, C. S. (2006). Student and teacher perspectives on classroom management. In C. M. Evertson \& C. S. Weinstein (Eds.), Handbook of classroom management: Research, practice, and contemporary issues (pp. 181-219). Mahwah, NJ: Lawrence Erlbaum Associates.

Publisher's Note Springer Nature remains neutral with regard to jurisdictional claims in published maps and institutional affiliations. 